\title{
Academic Resilience in College Students: Relationship between Coping and GPA
}

\author{
Tiwatope Tope-Banjoko \\ M.S., Virginia State University, USA, ttop4344@students.vsu.edu
}

Victoria Davis

M.S., Virginia State University, USA,vdav8678@students.vsu.edu

Kara Morrison

M.S., Virginia State University, USA, kmor8669@students.vsu.edu

John Fife

Ph.D., Virginia State University, USA, jfife@vsu.edu

Oliver Hill

Ph.D., Virginia State University, USA, ohill@vsu.edu

Cheryl Talley

Ph.D., Virginia State University, USA, ctalley@vsu.edu

\begin{abstract}
The Phenomenological Variant of Ecological Systems theory (PVEST) proposes that an individual's identity is formed as a result of the daily life events they experience and their cultural background (McGee \& Spencer, 2013; McGee \& Spencer, 2012; Spencer, 2011; Spencer et. Al, 2015). PVEST uses a systems-oriented human development perspective to maximize our understanding of not only resilience but also vulnerability and risk factors often experienced by marginalized youth (Talley, Scherer \& Hill, 2018). According to PVEST, the approach these individuals utilize to cope with these experiences, either adaptive or maladaptive contribute to identity formation. In this study, Mindfulness was explored as one possible adaptive coping mechanism to determine how well it predicts academic success. By operationalizing Mindfulness as an adaptive coping mechanism, we posited that adaptive coping would contribute positively to academic identity, measured as cumulative grade point average. The aim of this study was to determine how well mindfulness, cognitive-emotional regulation and selfhandicapping behaviours predict academic success in African American STEM students. This research is part of a larger longitudinal intervention aimed to increase retention of STEM majors. There was a total of 400 African American STEM students who participated in the study. Participants filled out questionnaires that measured self-handicapping, cognitive-emotional regulation, and mindfulness. The results reiterated the importance of incorporating self-regulation and mindfulness practices in education.
\end{abstract}

Keywords: coping, gpa, self-handicapping, cognitive-emotional regulation, mindfulness, pvest

\section{INTRODUCTION}

The Phenomenological Variant of Ecological Systems (PVEST) theory, developed by Dr. Margaret Spencer, proposes that all humans experience vulnerabilities and supports as a normal part of life. The theory also posits that both risk and protective factors contribute to an individual's identity formation

Citation: Tope-Banjoko, T., Davis, V., Morrison, K., Fife, J., Hill, O. \& Talley, C. (2020). Academic Resilience in College Students: Relationship between Coping and GPA. Anatolian Journal of Education, 5(2), 109-120. https://doi.org/10.29333/aje.2020.529a 
in the context of their culture and the daily life events they experience (McGee \& Spencer, 2013; McGee \& Spencer, 2012; Spencer, 2011; Spencer $e t$. Al, 2015). A combination of micro- and macro influences, developmental processes, interpersonal relationships and cognition-based perceptions yield either adaptive coping mechanisms (resilience) or maladaptive coping strategies. Over time a resulting identity is formed from these experiences and responses dictate their continued use: a habitual feedback loop (McGee \& Spencer, 2013; McGee \& Spencer, 2012; Spencer, 2011; Spencer et. Al, 2015). Some researchers have described academic identity as an important element in successful college experience (Cokley, McClain, Jones \& Johnson, 2011; Beasley, Chapman-Hilliard \& McClain, 2016). It is of interests to examine whether coping strategies, adaptive or maladaptive, are influential on academic outcomes (Chan, Poon \& Tang, 2016). In this study, PVEST is used to investigate the coping strategies that affect academic success.

Emotion regulation refers to the type of coping strategies that are used to reduce, maintain, or increase an emotion (Gross, 2001; Garnefski, Yanda van Rood, Carlijn de Roos \& Kraaij, 2017; Balzarotti, Biassoni, Villani, Prunas, Velotti, 2016). Emotional regulation comprises of a framework of four domains including self-awareness, self-management, social awareness and relationship management (Fernandez, Salamonson, Griffiths, 2012). Gross (2001) identifies nine cognitive-emotional regulation strategies to negative events. Positive coping strategies include the following: acceptance, positive refocusing, refocus on planning, positive reappraisal and putting into perspective (Gross 2001; Garnefski, Yanda van Rood, Carlijn de Roos \& Kraaij, 2017; Chana, Poon \& Tang, 2016). Negative coping strategies include self-blame, rumination, catastrophizing, and blaming others (Gross 2001; Garnefski, Yanda van Rood, Carlijn de Roos \& Kraaij, 2017). Positive coping has shown to be associated with resilience while negative coping is associated with depression and poor academic performance (Cromley, Perez, and Kaplan 2015). Specifically, catastrophizing is found as a predictor of anxiety and depressive symptoms. It is of interest to examine emotion regulation as it is viewed as a facilitator of self-regulated learning.

Academic self-regulation can be defined as self-regulated learning; that is, the motivational and behavioral processes allowing individuals to activate and sustain cognitions, behaviors, and emotions in a systematic way toward the attainment of their own learning goals (Abar, Carter \& Winsler, 2009). Self-regulated learners are those who understand the motives and strategies necessary for learning, and, implement those strategies in their learning process. For example, a student who is considered to be a self-regulated learner would know what study habits to employ when faced with a challenging course, while a student who is less self-regulatory would tend to give up on the course rather than try to figure out a way to work through the difficulty. The self-regulated student is more intrinsically motivated and feels able to succeed (Abar, Carter \& Winsler, 2009). Self-regulation is evident in influencing academic performance outcomes (Wilson \& Narayan 2014) and essential for directing goal-oriented behaviors necessary for successful academic performance (Karabenick \& Berger 2013). Self-regulation yields high performance and academic self-efficacy. That is self-regulation facilitates one's academic confidence and impacts performance outcomes such as course grades and GPA. Selfregulatory behavior also engages a student in critical thinking and problem solving. In addition, selfhandicapping has also been shown to be related with negative academic outcomes.

In academic achievement settings, self-handicapping is a form of maladaptive coping, and represent a frequently used strategy for regulating the threat to self-esteem elicited by the fear of failing (Kalyon, Dadandi \& Yazici, 2016). The goals of self-handicapping are to disregard ability as the causal factor for a poor performance and to embrace ability as the causal factor for a successful one (Hirt, McCrea \& Boris, 2003; Rappo, Alesi \& Pepi, 2017; Kalyon, Dadandi \& Yazici, 2016). Self-handicapping can be classified as obstacles which lower the likelihood of success, acquired obstacles, and obstacles that people claim to have, claimed obstacles. The term behavioral self-handicapping is used to describe acquired handicaps and self-reported handicaps to describe claimed handicaps. A common approach

Anatolian Journal of Education, October $2020 \bullet$ Vol.5, No.2 
used in self-handicapping is procrastination (Rappo, Alesi \& Pepi, 2017; Kalyon, Dadandi \& Yazici, 2016).

Academic self-handicapping refers to the act of creating obstacles or strategies that often impede successful performance of important tasks (Yavuzer, 2015). It is the process where people refrain from attempts when anticipate a failure in the result of tasks (Sultan \& Kanwal, 2014). The relationship between self-handicapping behavior and low achievement and performance outcomes are due to learning approaches. Self-handicapping behavior is more of an avoidance behavior where students engage in activities that hinder opportunities for effective learning such as avoiding seeking help from teachers, procrastinating, and cheating behavior (Urdan 2004; Wolters 2004; Yavuzer, 2015; Kalyon, Dadandi \& Yazici, 2016). Overall, self-handicapping behaviors are consistent with maladaptive learning and poor learning outcomes.

In this study, we conceptualize mindfulness as an adaptive coping mechanism. Mindfulness is the capacity to be fully aware of all that one experiences inside the self- body mind, heart, spirit, and to pay full attention to what is happening around us- people, the natural world, our surroundings and events (Boyatzis and McKee, 2005; Rodgers, 2014). Research states that people who deliberately practice mindfulness are consciously self-aware and self-monitoring; they are open and attentive to other people and to the world around them (McKee, et al.,2008). Research has shown that mindfulness is helpful in the moment of learning and also in more future-focused skills. By maintaining a calmer view of the present, students are able to improve their study habits, planning, and organizational skills through mindfulness (Broderick \& Jennings, 2012). The main objective of mindfulness is to establish focus, and focus is crucial to academic success. Like most skills, maintaining focus improves with practice, and students trained in mindfulness can better focus on the task or lesson at hand and filter out distractions (Rodgers, 2014). Research has shown that mindfulness is helpful in the moment of learning and also in more future-focused skills. By maintaining a calmer view of the present, students are able to improve their study habits, planning, and organizational skills through mindfulness (Broderick \& Jennings, 2012). Mindfulness education appears to have a positive impact on academic performance by helping students - even those with learning disabilities - focus, be more organized, plan ahead, perform better on exams, and think critically. It helps students improve their selfawareness, identify their feelings, and control their reactions.

Previous research indicates STEM attrition due to multiple personal factors that limits student's tolerance to deal with the demands that come with post-secondary education (Scherer, Talley \& Fife, 2017). The aim of this study was to determine how well mindfulness, cognitive-emotional regulation and self-handicapping behaviours predict academic success in African American STEM students. It was hypothesized that students who scored higher on subscales of the Patterns of Adaptive Learning (PALS) (Short form Self-Regulation Questionnaire (SSRQ), Cognitive-Emotional Regulation Questionnaire (CERQ), Five Facet Mindfulness Questionnaire (FFMQ) \& Self-Handicapping) that are associated with positive coping could be characterized as resilient students and would also have a higher cumulative GPA.

\section{METHOD}

\section{Participants}

This research is part of a larger longitudinal intervention aimed to increase retention of STEM majors. There was a total of 451 participants surveyed for this study. Once incomplete data was removed, there was data from 400 African American STEM students used in the study. $76.5 \%(N=306)$ of which were female, and $23.5 \%$ ( $N=94)$ of which were male, ranging from ages 18 to 35 ( $M=18.87$, $S D=1.89$ ). The students were STEM majors who were enrolled in either Biological Science (BIO 116) $(N=181)$ or Principles of Biology I (Bio 120) $(N=219)$ in the Fall 2017 semester. Of the 400 
participants, $76.5 \%$ (306) were females and $23.5 \%$ (94) were males. The sample consisted of majority African American participants (359 in total; 89.8\%).

Materials

\section{Self-Handicapping}

Patterns of Adaptive Learning Survey (PALS) (Midgley et al., 2000). The PALS is a self-report measure used to assess personal achievement goals and achievement related to beliefs, attitudes, and coping strategies. Student participants completed the six item Academic Self-handicapping subscale of the PALS. The Self-Handicapping subscale measures the use of self-sabotaging acts that impede academic performance (e.g. "Some students fool around the night before a test. Then if they don't do well, they can say that is the reason. How true is this for you?"). Responses to the Academic SelfHandicapping Scale are recorded on a 5-point Likert scale ranging from $1=$ "Not at all true" to $5=$ " Very true". Higher scores indicate that the student has a tendency to use self-sabotaging acts as an excuse for failure in the academic setting. The Self-Handicapping subscale of the PALS is reported to demonstrate a reliability of $\alpha=.91$ (Midgely et al., 2000).

\section{Cognitive-Emotional Regulation}

Cognitive emotional regulation was measured using the Cognitive Emotional Regulation Questionnaire (CERQ) (Garnefski, Kraaij, and Spinhoven 2001). The CERQ is a 36- item questionnaire which comprises nine subscales that relate to maladaptive or adaptive emotional coping strategies. The CERQ assesses emotion regulation strategies students use following a particular negative-event or situation. Maladaptive coping strategies within the CERQ include self-blame (" I feel that I am the one who is responsible for what has happened"), rumination (" I dwell upon the feelings the situation has evoked in me"), catastrophizing (" I continually think how horrible the situation has been"), and blaming others ("I feel that basically the cause lies with others"). Adaptive coping strategies include acceptance (" I think that I must learn to live with it"), positive refocusing (" I think about pleasant experiences") refocusing on planning (" I think of what I can do best") positive reappraisal (" I think I can learn something from the situation") and putting into perspective ("I think that it all could have been much worse"). It is important to note that each question within the CERQ is scored on a 5-point Likert scale ranging from $1=$ almost never to $5=$ almost always. Reliability coefficients for the nine subscales ranged from $\alpha=.93$.

\section{Five Facet Mindfulness Questionnaire (FFMQ)}

Mindfulness was measured using the FFMQ scale. FFMQ is a measure of mindfulness commonly used to assess change before and after MBIs. However, the stability and invariance of the FFMQ factor structure have not yet been tested before and after a Mindfulness Based Intervention (MBI). FFMQ items measure mindfulness across 5 factors, observation ("When I take a shower or bath, I stay alert to the sensations of water on my body"), describe ("I can easily put my beliefs, opinions, and expectations into words"), act with awareness items ("I find it difficult to stay focused on what's happening in the present"), nonjudge ("I believe some of my thoughts are abnormal or bad and I shouldn't think that way"), and nonreact ("In difficult situations, I can pause without immediately reacting"). It is important to note that each question within the FFMQ is scored on a 5-point Likert scale ranging from $1=$ never or very rarely true to $5=$ very often or always true. Reliability coefficients for the nine subscales ranged from $\alpha=.73$. 


\section{Academic success}

Academic success was measured by collecting student's cumulative GPA.

\section{Procedures}

Research was conducted in the biology department. Students were offered extra credit for their participation in the study. The Blackboard Learning Management System was used to distribute the assessment link to their students who were enrolled in introductory courses, Bio 116 and Bio 120. The assessment survey was administered through Qualtrics (2016) website. At the beginning of the assessment, a consent form was shown to ensure all participants were 18 years of age or older and that they understood their rights as a research participant. The assessment took approximately 20 to $25 \mathrm{~min}$ to complete. After all of the data was collected, Qualtrics generated an SPSS file. Student's identifying information were recoded, and each participant was assigned a participant number.

\section{FINDINGS}

\section{Descriptive Results}

\section{Association Between Cognitive-Emotional Regulation and Self-Handicapping}

A correlation matrix was used to determine the relationship between cognitive emotional regulation and self-handicapping (Table 1). There was a significant positive relationship between cognitiveemotional regulation and self-handicapping, with Pearson $\mathrm{r}=.20, \mathrm{p}<.05$. The results of the correlation indicate that as cognitive-emotional regulation increases, self-handicapping increases and vice versa. The positive relationship between self-handicapping and cognitive-emotional regulation was not expected, rather a negative relationship was expected due to the maladaptive nature of selfhandicapping.

Table 1

Correlation Matrix of the Relationship between Cognitive-Emotional Regulation and SelfHandicapping

\begin{tabular}{lllll}
\hline & Mean & Std. Deviation & CERQ & Self-Handicapping \\
\hline CERQ & 96.51 & 21.64 & & $.20^{* *}$ \\
Self-Handicapping & 2.66 & .98 & $.20^{* *}$ & 1 \\
\hline
\end{tabular}

To further investigate this relationship between self-handicapping and cognitive-emotional regulation, we examined the subscale in CERQ, which are grouped into two domains, adaptive coping strategies and maladaptive coping strategies. It was therefore hypothesized that the maladaptive domain of the cognitive-emotional regulation questionnaire, would be positively correlated with the selfhandicapping scale. A correlation matrix supported this hypothesis (Table 2). There was a significant positive relationship between the maladaptive domain of cognitive-emotional regulation and selfhandicapping, Pearson $r=.37, p<.001$. 
Table 2

Correlation Matrix of the Relationship between Domains in CERQ, Adaptive Coping Strategies \& Maladaptive Coping Strategies, and Self-Handicapping.

\begin{tabular}{llllll}
\hline & Mean & Std. Deviation & $\begin{array}{l}\text { Self- } \\
\text { Handicapping }\end{array}$ & $\begin{array}{l}\text { Maladaptive } \\
\text { Coping }\end{array}$ & $\begin{array}{l}\text { Adaptive } \\
\text { Coping }\end{array}$ \\
\hline Self-Handicapping & 2.66 & .98 & 1 & & \\
Maladaptive Coping & 34.84 & 10.26 & $.37^{* *}$ & 1 & \\
Adaptive Coping & 61.67 & 14.90 & .042 & $.46^{* *}$ & 1 \\
\hline
\end{tabular}

These findings warranted an in-depth analysis of the subscales of cognitive-emotional regulation. A correlation matrix was used to determine the individual relationship between self-handicapping and maladaptive coping scales (Table 3). The correlation matrix indicated that each of the four subscales of the maladaptive coping strategies were individually found to have a significant positive relationship with self-handicapping; Self-blame, $r=.18, p<.001$, Rumination, $r=.18, p<.001$, Catastrophizing, $r=.39, p<.001$, and Other blame, $r=.39, p<.001$. In the subscales of the adaptive domain, the correlation matrix showed a significant positive relationship between one of the five subscales; positive refocusing and self-handicapping, $r=.20, p<.001$.

Table 3

A Correlation Matrix of the Relationship between Self-Handicapping and Maladaptive Coping Scales

$\begin{array}{llrll}\text { Self- } & \text { Self- } & \text { Acceptance Rumination Positive } & \text { Refocus on Positive } & \text { Putting intoCatastrophizing Other } \\ \text { Handica } & \text { blame } & \text { RefocusingPlanning } & \text { Reappraisal } & \text { Perspective }\end{array}$
pping

\begin{tabular}{|c|c|c|c|c|c|c|c|c|c|c|c|c|}
\hline & Mean & $\begin{array}{l}\text { Std. } \\
\text { Deviation }\end{array}$ & & & & & & & & & & \\
\hline $\begin{array}{l}\text { Self- } \\
\text { Handicapping }\end{array}$ & 2.6642 & .97805 & 1 & & & & & & & & & \\
\hline Self-blame & 7.6350 & 2.59685 & $.182^{* *}$ & 1 & & & & & & & & \\
\hline Acceptance & 11.7275 & 3.45878 & .019 & $.592^{* *}$ & 1 & & & & & & & \\
\hline Rumination & 8.3600 & 2.48613 & $.184^{* *}$ & $.626^{* *}$ & $.604^{* *}$ & 1 & & & & & & \\
\hline $\begin{array}{l}\text { Positive } \\
\text { Refocusing }\end{array}$ & 11.5475 & 3.38843 & $.197^{* *}$ & $.342^{* *}$ & $.520^{* *}$ & $.484^{* *}$ & 1 & & & & & \\
\hline $\begin{array}{l}\text { Refocus on } \\
\text { Planning }\end{array}$ & 12.8475 & 3.49568 & -.029 & $.334^{* *}$ & $.585^{* *}$ & $.461^{* *}$ & $.692^{* *}$ & 1 & & & & \\
\hline $\begin{array}{l}\text { Positive } \\
\text { Reappraisal }\end{array}$ & 13.1750 & 3.88937 & -.056 & $.259^{* *}$ & $.558^{* *}$ & $.326^{* *}$ & $.628^{* *}$ & $.807^{* *}$ & 1 & & & \\
\hline $\begin{array}{l}\text { Putting into } \\
\text { Perspective }\end{array}$ & 12.3750 & 3.60512 & .060 & $.374^{* *}$ & $.557^{* *}$ & $.410^{* *}$ & $.589^{* *}$ & $.602^{* *}$ & $.661^{* *}$ & 1 & & \\
\hline Catastrophizing & 9.4225 & 3.68142 & $.389^{* *}$ & $.519^{* *}$ & $.394^{* *}$ & $.610^{* *}$ & $.402^{* *}$ & $.212^{* *}$ & .096 & $.246^{* *}$ & 1 & \\
\hline Other Blame & 9.4225 & 3.56451 & $.392^{* *}$ & $.412^{* *}$ & $.338^{* *}$ & $.478^{* *}$ & $.369^{* * *}$ & $.213^{* *}$ & $.113^{*}$ & $.204^{* * *}$ & $.797^{* *}$ & 1 \\
\hline
\end{tabular}

To determine the predictive relationship between cognitive-emotional regulation and selfhandicapping, a simple linear regression was conducted, with self-handicapping as the dependent variable and cognitive-emotional regulation as the predictor (Table 4). The results of the linear regression showed that cognitive emotional regulation significantly predicted self-handicapping, $(F(1,397)=17.02, P<.000)$ with $\mathrm{R}^{2}=.041$.

Table 4

A Simple Linear Regression Depicting the Predictive Relationship between Cognitive-Emotional $\underline{\text { Regulation and Self-Handicapping }}$

\begin{tabular}{llll}
\hline & $R^{2}$ & $F$ & Beta \\
CERQ & .041 & 17.02 & .203 \\
\hline
\end{tabular}

To test the path model to determine its fit with the data, the data were analysed using statistical software IBM Statistical Package for the Social Sciences 24 (SPSS) (2016) and IBM SPSS Amos. The 
goal of this study was to determine how well mindfulness, cognitive-emotional regulation and selfhandicapping behaviours predict academic success in African American STEM students. The predictor variables were mindfulness, cognitive-emotional regulation and self-handicapping, with self-regulation as the proposed mediating variable. The fit indices indicated that the model was a good fit with the data, with a chi-square value of 7.16, degrees of freedom $=3$, and $p<.067$; CFI value of .99, and RMSEA value of .059. All the paths in the analysis were significant. The path analysis indicated a positive relationship between CERQ and Self-handicapping (unstandardized beta=.23) and CERQ and Mindfulness (unstandardized beta=. 13) (Figure 1) (Table 5).

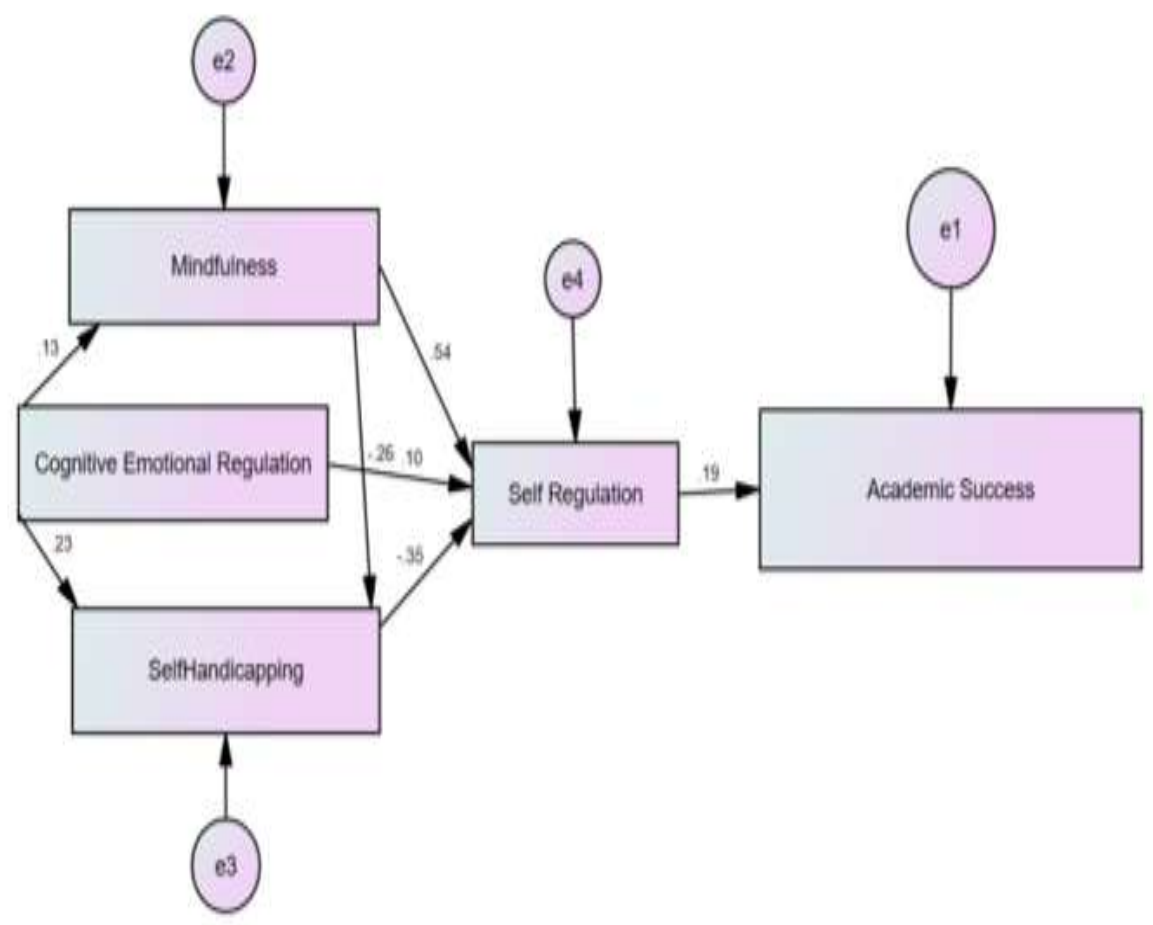

Figure 1

Anatolian Journal of Education, October $2020 \bullet$ Vol.5, No.2 
Table 5

Regression Weights: (Group number 1 - Default model)

\begin{tabular}{|c|c|c|c|c|c|c|c|}
\hline Model paths & & & b Estimate & B Estimate & S.E. & C.R. & $\mathrm{P}$ \\
\hline Mindfulness & $<--$ & $\begin{array}{l}\text { Cognitive-Emotional } \\
\text { Regulation }\end{array}$ & .009 & .125 & .003 & 2.521 & .012 \\
\hline $\begin{array}{l}\text { Self- } \\
\text { Handicapping }\end{array}$ & $<---$ & $\begin{array}{l}\text { Cognitive-Emotional } \\
\text { Regulation }\end{array}$ & .011 & $.234-$ & .002 & 4.899 & $* * *$ \\
\hline $\begin{array}{l}\text { Self- } \\
\text { Handicapping }\end{array}$ & $<--$ & Mindfulness & -.171 & -.28 & .032 & -5.412 & $* * *$ \\
\hline Self-Regulation & $<---$ & Mindfulness & 5.553 & .536 & .384 & 14.467 & $* * *$ \\
\hline Self-Regulation & $<---$ & Self-Handicapping & -5.414 & -.345 & .589 & -9.192 & $* * *$ \\
\hline Self-Regulation & $<---$ & $\begin{array}{l}\text { Cognitive-Emotional } \\
\text { Regulation }\end{array}$ & .073 & .104 & .026 & 2.810 & .005 \\
\hline GPA & $<--$ & Self-Regulation & .011 & .190 & .003 & 3.859 & $* * *$ \\
\hline
\end{tabular}

\section{CONCLUSION, DISCUSSION AND SUGGESTIONS}

The findings in this study highlight the important relationship between cognitive-emotional regulation and academic success. Within the PVEST framework, a student that has more maladaptive characteristics, (s)he is less likely to be successful in school than a student who has more adaptive characteristics. We used this supposition to support our hypothesis that there would be an inverse relationship between self-handicapping and academic success and that high grades would correspond with mindfulness.

The path model revealed a positive relationship between self-handicapping and cognitive-emotional regulation, which was not expected. Rather a negative relationship was expected due to the maladaptive nature of self-handicapping. It was therefore hypothesized that it was actually the Maladaptive Scale of the Cognitive-Emotional Regulation Questionnaire, that was positively correlated with the self-handicapping scale. The results of the correlation supported our hypothesis. There was a significant, positive relationship between maladaptive cognitive-emotional regulation and self-handicapping, Pearson $r=.34, p<.001$. The adaptive cognitive-emotional regulation was not significantly correlated with self-handicapping. These findings reveal the highly nuanced nature of affective factors. They also give credence to the PVEST model in that coping strategies were associated with and even predict academic outcomes.

Mindfulness is considered a healthy form of self-regulation because it is a cognitive state of awareness, where attention is in the present, and one accepts their experience without judgement (StLouis, Verner-Filion, Bergeron, \& Vallerand, 2016). The PVEST model explains that once there is stress engagement, such as daily hassles, reactive coping methods are utilized in an effort to cope with these stressors. The type of coping strategy an individual utilizes, maladaptive or adaptive, shapes a person's emergent identity (Spencer, 1995). Spencer (2011) argues that young Americans have difficulty developing attachment to their identity, due to the opposing experiences they have between their daily experiences and their beliefs about America. However, if an individual practices mindfulness, and is able to accept their experiences and how they chose to cope as separate from who they are without judgement, as defined by St-Louis, Verner-Filion, Bergeron, and Vallerand (2016), it will have more of an impact on positive identity formation than when mindfulness is absent. The path model shows how mindfulness interacts positively with self-regulation, a coping strategy. Since there is a positive relationship between mindfulness and coping, and the PVEST model shows a link 
between reactive coping methods and identity formation, it is important to explore how mindfulness, as a mediator, could impact identity formation.

The first limitation of this study was the uneven distribution of male and female participants. This grossly uneven gender distribution is a factor that could be a significant determinant in the outcome of the results. A study by Virtanen and Nevgi (2010), found that female participants had higher levels of self-regulation than male participants. The findings of this study were supported by Hosseini-Kamkar and Morton (2014) and Coyne, Vaske, Boisvert and Wright (2015), who found similar results. The second limitation was that, the sample was populated only by students who were enrolled in one of the two classes, Bio 116 or Bio120, in the Fall 2017 semester. Though each class had multiple sections, results of this study cannot be successfully generalized to other STEM classes. For future study, different classes in the STEM field during multiple semesters should be considered as part of the study to get a variety of STEM majors across different semesters, in turn, increasing the generalizability of the results.

Finally, the current study supports the use of predictive modelling, as a strategy in testing theoretical models, such as the PVEST model. There is a debate that pertains to researchers using predictive or causal language in research where predictive research is not the primary research focus. In the article by Shmueli (2010), attention was given to the predictive and causal verbiage that is often used by researchers to explain the outcomes of nonpredictive research, i.e. when researchers did not use predictive modelling. In this study a theoretical model was used, the PVSEST model, to understand and conceptualize the findings.

The aim of this study was to determine how well mindfulness, cognitive-emotional regulation and selfhandicapping behaviours predict academic success in African American STEM students. It was hypothesized that students who scored higher on subscales of the Patterns of Adaptive Learning (PALS) (SSRQ, CERQ, FFMQ \& SH) that are associated with positive coping could be characterized as resilient students and would also have a higher cumulative GPA. The findings suggest that that students who scored higher on the PALS subscales had better positive coping strategies, in turn had higher cumulative GPAs. The current study also highlights the importance of self-regulation practices in academic success by incorporating mindfulness practices as a coping strategy. It is important for educational institutions to incorporate mindfulness practices and self-regulation practices into their curriculum, in an effort to increase tolerance for the demanding nature of postsecondary education, in turn decreasing the rate of STEM attrition.

\section{REFERENCES}

Balzarotti, S., Biassoni, F., Villani, D., Prunas, A., \& Velotti, P. (2014). Individual differences in cognitive emotion regulation: implications for subjective and psychological well-being. Journal of Happiness Studies, 17(1), 125-143. doi:10.1007/s10902-014-9587-3

Abar, B., Carter, K.L., Winsler, A. (2009). The effects of maternal parenting style and religious commitment on self-regulation, academic achievement, and risk behavior among African American parochial college students. Journal of Adolescence. 32(2), 259-273.

Beasley, S. T., Chapman-Hilliard, C., \& McClain, S. (2016). Linking the emancipatory pedagogy of Africana/Black studies with academic identity outcomes among Black students attending PWIs. Journal of Pan African Studies, (8), 9. Retrieved from http://search.ebscohost.com.vsu.idm.oclc.org/login.aspx?direct=true \&db=edsglr\&AN=edsgcl.4726806 07\&site=eds-live 
Boyatzis, R., \& McKee, A. (2005). Resonant leadership. Boston, MA: Harvard Business School

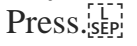

Broderick, P., \& Jennings, P. (2012). Mindfulness for adolescents: A promising approach to supporting emotion regulation and preventing risky behavior. New Directions for Youth Development, 2012(136), 111-126.

Chan, S. M., Poon, S. F., \& Tang, E. M. (2016). Daily hassles, cognitive emotion regulation and anxiety in children. Vulnerable Children and Youth Studies,11(3), 238-250. doi:10.1080/17450128.2016.1214887

Cokley, K., McClain, S., Jones, M., \& Johnson, S. (2011). A preliminary investigation of academic disidentification, racial identity, and academic achievement among african american adolescents. High School Journal,95(2), $54 . \quad$ Retrieved from http://search.ebscohost.com.vsu.idm.oclc.org/login.aspx?direct=true \&db=f5h\&AN=70199157\&site=e ds-live

Coyne, M. A., Vaske, J. C., Boisvert, D. L., \& Wright, J. P. (2015). Sex differences in the stability of self-regulation across childhood. Journal of Developmental and Life-Course Criminology,1(1), 4-20. doi:10.1007/s40865-015-0001-6

Cromley, J. G., Perez, T., Kaplan, A. (2015). Undergraduate STEM achievement and retention: cognitive, motivational and institutional factors and solutions, Policy Insights from the Behavioral and Brain Sciences 3,1,4-11. DOI: 10.1177/2372732215622648.

Fernandez, R., Salamonson, Y., Griffiths, R. (2012). Emotional intelligence as a predictor of academic performance in first-year accelerated graduate entry nursing students. Journal of clinical nursing. 21(23-24), 3485-3492.

Garnefski, N., Rood, Y. V., Roos, C. D., \& Kraaij, V. (2017). Relationships between traumatic life events, cognitive emotion regulation strategies, and somatic complaints. Journal of Clinical Psychology in Medical Settings,24(2), 144-151. doi:10.1007/s10880-017-9494-y

Gross, J. J. (2001). Emotion regulation in adulthood: timing is everything. Current Directions in Psychological Science, 10(6), 214-219. doi:10.1111/1467-8721.00152

Hirt, E. R., McCrea, S. M. \& Boris, H. I. (2003). “I know you self-handicapped last exam": Gender differences reactions to self-handicapping. Journal of Personality and Social Psychology, 84, 177193. DOI: $10.1037 / 0022-3514.84 .1 .177$

Hosseini-Kamkar, N., \& Morton, J. B. (2014). Sex differences in self-regulation: An evolutionary perspective. Frontiers in Neuroscience, 8 . doi:10.3389/fnins.2014.00233

Karabenick, S., \& Berger, J. (2013). Help seeking as a self-regulated learning strategy. Applications of Self-regulated Learning across Diverse Disciplines: A Tribute to Barry J. Zimmerman,237-261.

Kalyon, A., Dadandi, I., \& Yazici, H. (2016). The relationships between self-handicapping tendency and narcissistic personality traits, anxiety sensitivity, social support, academic achievement. Dusunen Adam: The Journal of Psychiatry and Neurological Sciences, 237-246. doi:10.5350/dajpn2016290305

McGee, E. O., \& Spencer, M. B. (2013). The development of coping skills for science, technology, engineering, and mathematics students: Transitioning from minority to majority environments. Urban 
Ills: Post Recession Complexities of Urban Living in the Twenty First Century, 351-378. Retrieved from https://repository.upenn.edu/gse_pubs/265.

McGee, E., \& Spencer, M. B. (2012). Theoretical analysis of resilience and identity. Thinking comprehensively about education: Spaces of educative possibility and their implications for public policy, 161.

McKee, A., Boyatzis R., \& Johnston, F. (2008). Becoming a resonant leader: Develop your emotional intelligence, renew your relationships, sustain your effectiveness. Boston, MA: Harvard Business Press.'in:

Rappo, G., Alesi, M., \& Pepi, A. (2016). The effects of school anxiety on self-esteem and selfhandicapping in pupils attending primary school. European Journal of Developmental Psychology, 14(4), 465-476. doi:10.1080/17405629.2016.1239578

Rodgers, L. (2014). A calmer happier kid. Scholastic Parent \& Child, 21(6), 60-63.

Scherer, S., Talley, C. P., \& Fife, J. E. (2017). How personal factors influence academic behavior and GPA in African american stem students. SAGE Open,7(2), 215824401770468. doi: $10.1177 / 2158244017704686$

Shmueli, G. (2010). To explain or to predict? Statistical Science, 25(3), 289-310. doi: 10.1214/10sts330

Spencer, M. B. (2011). American identity: Impact of youths' differential experiences in society on their attachment to American ideals. Applied Developmental Science, 15(2), 61-69.

Spencer, M., Harpalani, V., Cassidy, E., Jacobs, C. Y., Donde, S., Goss, T. N., ... \& Wilson, S. (2015). Understanding vulnerability and resilience from a normative developmental perspective: Implications for racially and ethnically diverse youth. Developmental Psychopathology: Volume One: Theory and Method, 627-672.

St-Louis, A. C., Verner-Filion, J., Bergeron, C. M., \& Vallerand, R. J. (2016). Passion and mindfulness: Accessing adaptive self-processes. The Journal of Positive Psychology, 13(2), 155-164. doi: 10.1080/17439760.2016.1245771

Sultan, S., \& Kanwal, F. (2014). Gender differences in self-handicapping: the role of self-esteem and fear of negative evaluation 3. Biannual Journal of Gender and Social Issues, 13(1), 45-56.

Talley, C., Scherer, S., \& Hill, O., "The role of PVEST as a Conceptual Framework for a Mindfulness Intervention: SSEHV at the College Level.” Unpublished Chapter, 2018.

Urdan, T. (2004). Predictors of academic self-handicapping and achievement: examining achievement goals, classroom goal structures, and culture. Journal of Educational Psychology, 251-264.

Virtanen, P., \& Nevgi, A. (2010). Disciplinary and gender differences among higher education students in self-regulated learning strategies. Educational Psychology,30(3), 323-347. doi:10.1080/01443411003606391

Wilson, K., \& Narayan, A. (2014). Relationships among individual task self-efficacy, self-regulated learning strategy use and academic performance in a computer-supported collaborative learning environment. Educational Psychology,36(2), 236-253. doi:10.1080/01443410.2014.926312 
Yavuzer, Y. (2015). Investigating the relationship between self-handicapping tendencies, self-esteem and cognitive distortions. Educational Sciences: Theory \& Practice, 15(4), 879-890. 